\title{
Analysis and Evaluation of Competitiveness in Medical Tourism Industry in Taiwan
}

\author{
Yen-Hung Chen*, Tin-Chang Chang \\ Department of Business Administration, Asia University, 500, Lioufeng Rd., Wufeng, Taichung, 41354, Taiwan
}

\begin{tabular}{l} 
A R T I C L E I N F O \\
\hline Article history: \\
Received: 09 November, 2020 \\
Accepted: 20 December, 2020 \\
Online: 28 December, 2020 \\
\hline
\end{tabular}

Keywords:

Medical Tourism

Hospital Management

VIKOR

Entropy

SWOT

COVID-19

\begin{abstract}
A B S T R A C T
Tourism is relatively high profit, low-cost and high work opportunity industry. Medical tourism is special kind of business type in tourism industry. The characteristic of medical tourism is high threshold and high profit for hospital and government. But, fewer literatures research about competitiveness of medical tourism industry until now. Especially, medical tourism industry faces big challenge when COVID-19 occurs which stop patient to go abroad for treating in the world. This research arranges relative literatures and invite some expert's opinion to design criteria for evaluating competitiveness of medical tourism industry in each area. After that, linguistic VIKOR and Entropy will be integrated to analyze and evaluate performance of medical tourism industry among China, Taiwan, Japan and South Korea. Finally, some reasonable suggestion will be provided for Taiwan government and hospital.
\end{abstract}

\section{Introduction}

Compare with other area in Asia, medical service in Taiwan is relatively good whose price-performance ratio is high in the world. Based on health care index from CEOWORLD magazine, the rank of Taiwan is in top levels among eighty regions in the world (Please refer to Figure 1). This magazine investigates and believe that Taiwan's health care standard ranks first in medical equipment, medical personnel technology and medical expenses fields. Based on this information, Taiwan government can consider to apply this strength of Taiwan medical service to develop economics.

Business volume of tourism relative industry such as accommodation industry, transportation industry, catering industry and amusement industry will increase when government develop tourism industry [2]. Besides, a huge amount of work opportunity can be generated by tourism industry. Based on above reason, medical tourism become the main development business activity in Taiwan. However, medical tourism industry faces big challenge when COVID-19 occurs which stop tourist to travel in the world and foreign patient can't go to Taiwan for treatment [3]. It needs a novel criteria and framework to evaluate competitiveness of medical tourism industry for satisfying the sustainable development goal. The goal (research objectives) of this research is to develop a framework to evaluate and understand

"Corresponding Author: Yen-Hung Chen, chenyenhung1234@gmail.com competitiveness of medical tourism industry under the sustainability development condition in Taiwan.

The content of this research is organized as follows. Some literatures about medical tourism evaluation will be arranged and discussed in chapter 2. After that, some operation content about linguistic variable and proposed method will be explained in chapter 3 . The competitiveness of medical tourism industry among China, Taiwan, Japan and South Korea will be analyzed and evaluated based on proposed method and SWOT analysis about Taiwan medical tourism industry will be executed in chapter 4 . Some management implementation will be token over in chapter 5. Finally, conclusion and future research will be discussed as ending.

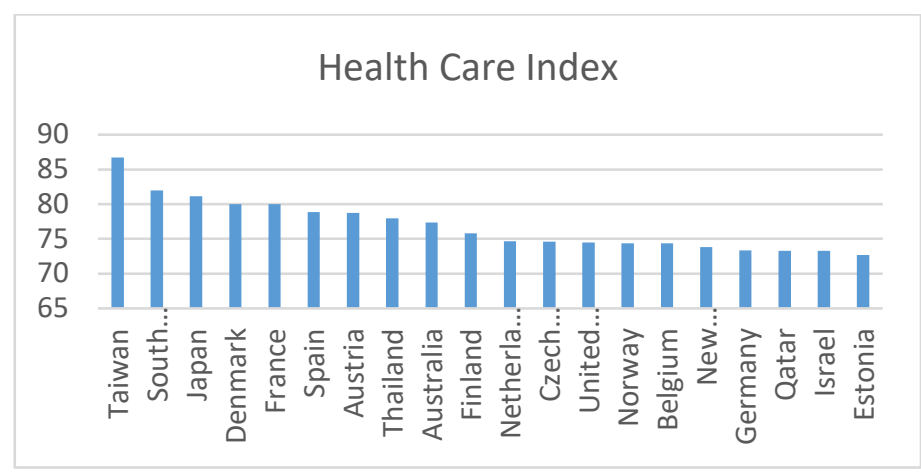

Figure 1: Rank of medical service in the world [1] 


\section{Literature Review}

In 2005, the business volume of global medical market and healthcare market reached US\$200-300 billion. In the same time point, the tourist volume of the global medical tourism industry market exceeds 19 million person per year and business volume of medical tourism industry approaches US $\$ 20$ billion [4]. Enterprise in medical tourism industry should manage and evaluate its performance. So, there are various literatures research about medical tourism evaluation has been executed under this development trend. Below literatures are relative research about medical tourism evaluation.

In [5], the author collected relative literatures and surveyed relative experts' opinions to build 33 evaluation criteria. And then, fuzzy VIKOR were applied to evaluate service quality of public medical tourism hospital. In [6], the author developed a comprehensive framework to assess the factors affecting health tourism development in Yazd province in China. Their method integrated interpretive structural modeling (ISM) with fuzzy TOPSIS to evaluate medical tourism competitive ability. Research result showed that patient satisfaction is the most important factors for developing medical tourism. In [7], the author tried to validate the measurement model for medical tourism research. In their research, the research dimension about human capital, physical infrastructure and patient satisfaction had been validated by confirmatory factor analysis (CFA). Future scholar can use their questionnaire to test performance of medical tourism industry. In [8], the author used strengths, weaknesses, opportunities and threats (SWOT) analysis to evaluate business status of medical tourism industry in Turkey. After that, analytical hierarchy process (AHP) were applied to analyze and rank the importance of each factor which will influence the development of tourism industry in Turkey.

In [9], the author took Indian medical tourism hospital as research target. This scholar applied SWOT analysis to evaluate the development status of each organization. And then, technique for order preference by similarity to ideal solution (TOPSIS) were combined with AHP to rank the performance of each hospital. In [10], author considered that medical tourism industry is normal business phenomenon because some country face long waiting queues, high treatment costs or lack of insurance in some country. They applied SWOT model and best-worst techniques to develop and analyze medical tourism industry development strategy in Yazd province of Iran. In [11], the author collected relative information of different city in India and used rough number to integrate experts' opinions. Analytic hierarchy process was applied to evaluate weigh of each medical tourism criteria and multi - attributive border approximation area comparison methods were used to rank performance of medical tourism site. According to analysis result, we can know that "quality of infrastructure of healthcare institutions", "supply of skilled human resources" and "new job creations" were three most important factor to select medical tourism destination. In [12], the author collected relative information to build medical tourism evaluation criteria and investigated fuzzy TOPSIS with decision making trial and evaluation laboratory (DEMATEL) to analyze the key factor for developing medical tourism industry in Malaysia. According to their research result, human and technological factors are most important key factors for medical tourism industry. In [13], author used SERVQUAL methodology to evaluate service quality of hospital and designed twenty-eight criteria to build hospital service quality. Fuzzy AHP and Elimination and Choice Translating Reality (ELECTRE-I) were employed to evaluate and rank performance of each hospitals. According to experiment result, trustworthiness and empathy were the most important dimension for patient to select hospital.

According to above information, we can know that a lot of literatures discuss about medical tourism in each dimension. They used each kind of multi criteria decision making technology to handle each kind medical tourism evaluation problem (such as importance factor analysis, medical service evaluation, hospital performance evaluation and hospital destination decision etc). However, past literatures investigative about medical tourism evaluation problem who usually lack to consider the dimension about sustainable development of medical tourism industry when some special event will stop development of medical tourism such as COVID-19. This study will fill this research gap.

\section{Preliminary and Entropy-VIKOR Method}

In this study, we will introduce the research tool - SWOT analysis, linguistic variable, entropy method and Entropy-VIKOR Method.

\subsection{SWOT analysis}

Strengths, Weaknesses, Opportunities and Threats Analysis (SWOT Analysis) are the most useful analysis tool. This tool has been applied in each kind of fields such as hospitality industry evaluation [14], tourism development strategy [15], medical tourism assessment [8] etc. SWOT is the comprehensive analysis tool which think over relative conditions of relevant competitors and external environmental conditions of research target. This method allows research target to analyze, examine and investigate external opportunities and potential threats. After that, research target will understand and recognize their own advantages and disadvantages for analyzing its competitiveness (Refer to Table 1).

Table 1: SWOT analysis concept

\begin{tabular}{|l|l|l|l|}
\hline \multicolumn{2}{|c|}{} & \multicolumn{2}{|l|}{ Impact on Research Target } \\
\cline { 3 - 4 } \multicolumn{2}{|c|}{} & $\begin{array}{l}\text { Good for } \\
\text { Research } \\
\text { Target }\end{array}$ & $\begin{array}{l}\text { Harmful to } \\
\text { Research } \\
\text { Target }\end{array}$ \\
\hline $\begin{array}{l}\text { Sources of } \\
\text { Influencing } \\
\text { Factors }\end{array}$ & $\begin{array}{l}\text { Within the } \\
\text { Research } \\
\text { Target }\end{array}$ & Strengths & Weaknesses \\
\cline { 2 - 4 } & $\begin{array}{l}\text { External } \\
\text { Environment }\end{array}$ & Opportunities & Threats \\
\hline
\end{tabular}

\subsection{Linguistic Variable}

Linguistic variable is useful tool. This tool can let expert to express their opinion under the same evaluation scale and integrate experts' opinion easily [16]. Below content are the definition, notation and operation about linguistic variable.

Definition 1. The $\eta$ scale linguistic term set $S$ is the set of linguistic variables. S can be described by following equation [17] and [18]. 


$$
\mathrm{S}=\left\{s_{0}^{\eta}, s_{1}^{\eta}, \ldots, s_{\eta-1}^{\eta}\right\}
$$

where $s_{7}^{\eta}(\neg=0,1, \ldots, \eta-1)$ is $\eta$ scale linguistic variable and $\eta$ is the total volume of linguistic variable in $\mathrm{S}$.

Definition 2. $\Delta$ is the linguistic transfer function. This function can transfer linguistic variable into crisp value $\mathrm{n}$ ( $\mathrm{n}$ is between 0 and 1). This function can be described by following equation [17] and [18].

$$
\Delta\left(s_{z}^{\eta}\right)=\frac{z}{\eta-1}=\mathrm{n}
$$

Definition 3. $\Delta^{-1}$ is the linguistic transfer inverse function. This function can transfer crisp value $\mathrm{n}$ ( $\mathrm{n}$ is between 0 and 1 ) into linguistic variable. This function can be described by following equation [17] and [18].

$$
\triangle^{-1}(n)=s_{n *(\eta-1)}^{\eta}
$$

\subsection{Entropy Method}

Entropy Method is one kind of weight evaluation technology. Under this method, importance of each criterion will be decided according to information volume in each criterion. So, multi criteria decision making (MCDM) technology integrated with entropy method can distinguish the performance of each alternative easily [19]. Below content are notation and operation about entropy method.

Definition 4. Suppose that $\varphi_{q}$ is entropy value for criterion q. If information in criterion q is low, then $\varphi_{q}$ is low. Entropy function should be described by following equation [20] and [21].

$$
\varphi_{q}=-1 * \frac{1}{\ln M} \sum_{i=1}^{M} f_{i q} \ln \left(f_{i q}\right)
$$

where $f_{g q}=\frac{x_{g q}}{\sum_{i=1}^{M} x_{i q}}$.

Definition 5. Weight (importance) of each criterion should be decided by entropy value. The weight of criterion q will be acquired by following equation [20] and [21].

$$
w_{q}=\frac{1-\varphi_{q}}{\sum_{z=1}^{N}\left(1-\varphi_{z}\right)}
$$

where $\mathrm{N}$ is the total volume of criteria.

\subsection{Entropy-VIKOR Method}

In this research, Entropy-VIKOR Method are selected to cope with medical tourism competitiveness evaluation problem. In Entropy-VIKOR Method, some notation will be applied and can

\begin{tabular}{|c|c|c|}
\hline $\begin{array}{l}\text { Decision } \\
\text { matrix }\end{array}$ & $\begin{array}{c}\mathrm{X}= \\
\begin{array}{ccccc}C_{1} & C_{2} & \ldots & C_{n} \\
T_{1} \\
T_{2} \\
\ldots \\
T_{m}\end{array}\left[\begin{array}{cccc}\tilde{x}_{11} & \tilde{x}_{12} & \ldots & \tilde{x}_{1 n} \\
\tilde{x}_{21} & \tilde{x}_{22} & \ldots & \tilde{x}_{2 n} \\
\ldots & \ldots & \ldots . & \ldots \\
\tilde{x}_{m 1} & \tilde{x}_{m 2} & \ldots & \tilde{x}_{m n}\end{array}\right]\end{array}$ & $\begin{array}{l}\tilde{x}_{i j} \text { represents } \\
\text { performance of } \\
\text { research target } \\
T_{i} \text { with respect } \\
\text { to } C_{j} .\end{array}$ \\
\hline Expert & $\mathrm{E}=\left\{E_{1}, E_{2}, \ldots, E_{K}\right\}$ & $\begin{array}{l}K \text { represents } \\
\text { volume of } \\
\text { experts }\end{array}$ \\
\hline
\end{tabular}
be described as Table 2 .

Table 2: Notation in Entropy-VIKOR Method

\begin{tabular}{|l|l|l|}
\hline Set & Notation & $\begin{array}{l}\text { Detail } \\
\text { Description }\end{array}$ \\
\hline $\begin{array}{l}\text { Research } \\
\text { target }\end{array}$ & $\mathrm{T}=\left\{T_{1}, T_{2}, \ldots, T_{m}\right\}$ & $\begin{array}{l}m \text { represents } \\
\text { volume of } \\
\text { research target }\end{array}$ \\
\hline Criteria & $\mathrm{C}=\left\{C_{1}, C_{2}, \ldots, C_{n}\right\}$ & $\begin{array}{l}n \text { represents } \\
\text { volume of } \\
\text { criteria }\end{array}$ \\
\hline $\begin{array}{l}\text { Weight } \\
\text { criteria }\end{array}$ & $\mathrm{W}=\left\{w_{1}, w_{2}, \ldots, w_{n}\right\}$ & $\begin{array}{l}n \text { represents } \\
\text { volume of } \\
\text { criteria }\end{array}$ \\
\hline
\end{tabular}

$\underline{\text { www.astesj.com }}$
At first, research targets should be decided by organization. Organization should organize the evaluation project team. After that, some experts will be invited into this team. After experts discuss with each other, criteria for evaluating competitiveness of medical tourism industry can be arranged and selected. And then, experts' opinion will be gathered for evaluating performance of each research target respect to each criterion. At last, EntropyVIKOR method will be used to evaluate competitiveness of medical tourism industry among each research target in Asia. SWOT analysis will be executed for detailly evaluating competitiveness of medical tourism industry among each research target. Research result will be provided to organization for reference. Relative execution process can refer to Figure 2.

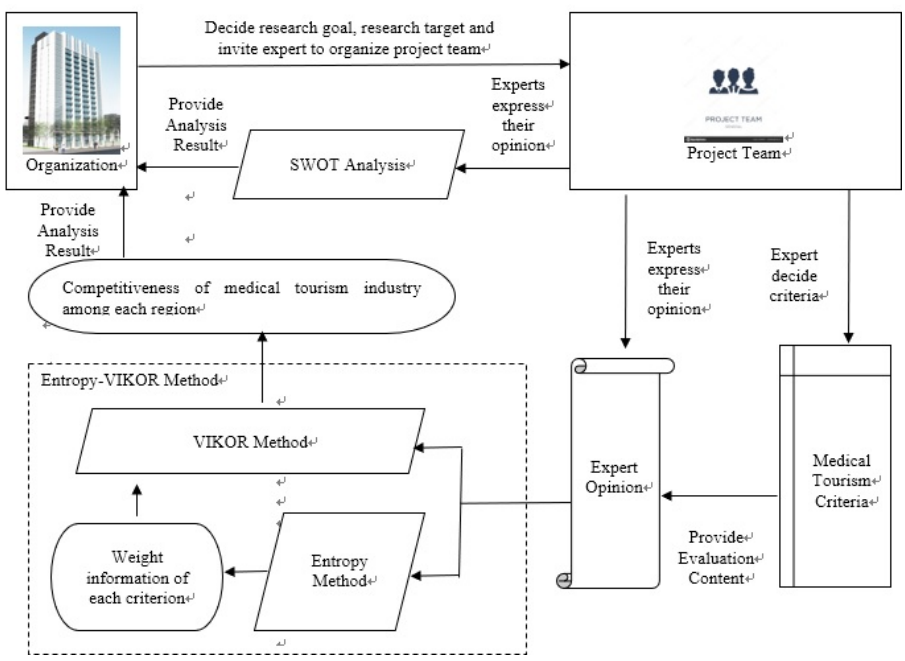

Figure 2: Execution process of proposed method

Let $\tilde{x}_{i j k}$ be expert k's opinion for performance of region i with respect to criterion j. Experts' opinion will be integrated by following equation.

$$
\tilde{x}_{i j}=\triangle^{-1}\left(\sum_{k=1}^{K} \frac{\Delta\left(\tilde{x}_{i j k}\right)}{K}\right)
$$

In this research, weight of criteria will be calculated and acquired by entropy method. Weight evaluation function can be describing according to following equation.

$$
w_{q}=\frac{1-\varphi_{q}}{\sum_{Z=1}^{n}\left(1-\varphi_{z}\right)}
$$

where $L_{i q}=\frac{\Delta\left(\tilde{x}_{i q}\right)}{\sum_{i=1}^{m} \Delta\left(\tilde{x}_{i q}\right)}, \varphi_{q}=-1 * \frac{1}{\ln (m)} \sum_{i=1}^{m} L_{i q} \ln \left(L_{i q}\right)$.

The advantage of using entropy method to acquire the weight of each criteria is that entropy method can decide the weight of each criteria automatically for reducing the evaluation burden of experts. 
Below content is relative execution step in VIKOR method.

Positive ideal solution (PIS) is the importance index in VIKOR method. PIS represents the ideal performance of virtual best research target (alternative). PIS can be calculated according to following equation.

$$
f_{j}^{*}=\max _{i} \triangle^{-1}\left(\tilde{x}_{i j}\right)
$$

Negative ideal solution (NIS) is another importance index in VIKOR. NIS represents the poorest performance of virtual worst research target (alternative). NIS can be calculated according to following equation.

$$
f_{j}^{-}=\min _{i} \triangle^{-1}\left(\tilde{x}_{i j}\right)
$$

Total performance of research target (the largest group utility) $S_{i}$ represents the overall performance of research target $T_{i}$. $S_{i}$ can be calculated according to following equation.

$$
S_{i}=\sum_{j=1}^{n} w_{j} * \frac{f_{j}^{*}-\Delta^{-1}\left(\tilde{x}_{i j}\right)}{f_{j}^{*}-f_{j}^{-}}
$$

The individual regret value of research target (the smallest individual regret) $R_{i}$ represents the maximum regret degree of decision maker if he/she select research target $T_{i} . R_{i}$ can be calculated according to following equation.

$$
R_{i}=\max _{j}\left[w_{j} * \frac{f_{j}^{*}-\Delta^{-1}\left(\tilde{x}_{i j}\right)}{f_{j}^{*}-f_{j}^{-}}\right]
$$

Total performance of research target $S_{i}$ and individual regret value of research target $R_{i}$ respectively means different consideration for making decision. So, expert can rank the performance of research target according to largest group utility $S_{i}$ and smallest individual regret $R_{i}$ simultaneously. Based above view point, it generates the compromise result $Q_{i} . Q_{i}$ should be calculated for ranking performance of each research target based on following equation.

$$
Q_{i}=\mathrm{V} * \frac{S_{i}-S^{*}}{S^{-}-S^{*}}+(1-\mathrm{v}) * \frac{R_{i}-R^{*}}{R^{-}-R^{*}}
$$

where v represents decision parameter. This parameter is used to make decision for adjusting the importance between $S_{i}$ and $R_{i}$. $S^{*}=\min _{i} S_{i}, S^{-}=\max _{i} S_{i}, R^{*}=\min _{i} R_{i}, R^{-}=\max _{i} R_{i}$.

Research target $T_{i}$ will be better if $Q_{i}$ is fewer.

\section{Competitiveness Analysis of Medical Tourism Industry Among Asia Region}

Competitiveness of medical tourism industry in Taiwan will be evaluated by an organization. After discussing and considering, four regions have been chosen as research target to evaluate their competitiveness. Those research targets are South Korea $\left(T_{1}\right)$, Japan $\left(T_{2}\right)$, Taiwan $\left(T_{3}\right)$, China $\left(T_{4}\right)$. Above research target are regions in Asia which are main medical tourism competitor for Taiwan.

The execution process of proposed method is as follows: Step 1. Organize evaluation project team

www.astesj.com
In the beginning, Taiwan government organize evaluation project team and invite nine experts to execute this evaluation project. Experts in this team include government officer, employees in traditional hotel, employees in travel agency, nurse leader, doctor (hospital dean) and university professors. The investigation target covered already include tourism industry, medical industry, government and university. So, respondents in this survey are representative (Refer to Table 3 ).

Table 3: Interviewee related information

\begin{tabular}{|l|l|l|}
\hline no & attribute & Content \\
\hline 1 & Industry & Hospital dean \\
\hline 2 & Industry & Nurse leader \\
\hline 3 & Industry & High level employees in travel agency \\
\hline 4 & Industry & High level employees in hotel \\
\hline 5 & Government & Staff in the Ministry of Economy \\
\hline 6 & Government & Staff in Tourism Bureau \\
\hline 7 & Government & $\begin{array}{l}\text { Staff in the Ministry of Health and } \\
\text { Welfare }\end{array}$ \\
\hline 8 & Academia & $\begin{array}{l}\text { Professor in department of business } \\
\text { management }\end{array}$ \\
\hline 9 & Academia & $\begin{array}{l}\text { Professor in department of nursing } \\
\text { management }\end{array}$ \\
\hline
\end{tabular}

Step 2. Execute evaluation criteria decision

After collecting literatures and experts discuss with each other, eight criteria are employed to evaluate performance of research target. The criteria include medical industry image $\left(C_{1}\right)$, medical ability $\left(C_{2}\right)$, telemedicine ability $\left(C_{3}\right)$, medical cost $\left(C_{4}\right)$, financial status in hospital and travel agency $\left(C_{5}\right)$, volume of medical tourism traveler per year $\left(C_{6}\right)$, medical service speed in hospital $\left(C_{7}\right)$ and maximum service volume in region $\left(C_{8}\right)$. Above criteria are suitable to evaluate competitiveness of medical tourism industry because of below reason.

(a) medical industry image

Patient's medical industry image in this region will influence his/her intention to go to the region [22] and [23], foreign hospital does not have opportunity to service this patient if he/her do not go to this region.

(b) medical ability

Some patients want to receive high quality medical service, so medical ability of medical industry in this region is the main consideration when patients select medical tourism destination region [24] and [25].

(c) telemedicine ability

Hospitals need to treat their foreign patients and maintain relationship with those patients. However, COVID-19 causes that medical tourism patient cannot go abroad to receive face-to -face medical service. So, telemedicine ability is more and more important for region to develop medical tourism industry in order to maintain relationship with foreign patients and continuously treat those patients.

(d) medical cost

In some region, medical cost is very expensive for citizen [26] and [27]. So, patient has the intention to cure his/her disease in foreign region. Medical cost is the main consideration for choosing medical tourism destination region.

(e) financial status in hospital and travel agency 
Some hospital's business volume decreases because COVID19 occurs and foreign patient cannot go abroad to receive medical service. So, robust financial status in hospital and travel agency is key factor if medical tourism industry wants to sustainable development.

(f) volume of medical tourism traveler per year

Volume of medical tourism traveler in this region is the important index to evaluate medical tourism development in this region. High volume of medical tourism traveler not only can reduce medical cost but also can increase potential foreign patient because medical tourism traveler will execute "buzz marketing" if this traveler satisfies medical service in this region.

(g) medical service speed in hospital

Foreign patients go abroad for receiving medical service will request service quality. In some literatures, it justified that medical service time will negative influence patient safety and service quality perception [28]. So, controlling medical service speed in the reasonable range is the important competitiveness of hospital and it will influence the development of medical tourism industry in this region.

(h) maximum service volume in the region

The maximum medical service volume in the region is important index because this index will decide maximum business volume of medical tourism industry in this region. According to scale economics view point, high business volume of medical tourism industry can reduce medical cost in this region because hospital can purchase a huge amount of medicine and medicine price will reduce by bulk purchase [29].

\section{Step 3. Collect information}

In this study, nine scale linguistic variables are employed for experts to express their opinions [30] and [31]. Expert's opinion about competitiveness of each research target (region) in medical tourism industry respect to each criterion can refer to Table 4.

Table 4: Performance of each research target

\begin{tabular}{|c|c|c|c|c|c|c|c|c|}
\hline & \multicolumn{4}{|c|}{ Expert 1's opinion } & \multicolumn{4}{|c|}{ Expert 2's opinion } \\
\hline & \begin{tabular}{|l|} 
South \\
Korea
\end{tabular} & Japan & Taiwan & China & $\begin{array}{l}\text { South } \\
\text { Korea }\end{array}$ & Japan & Taiwan & China \\
\hline$C_{1}$ & EG & EG & $\mathrm{P}$ & MG & MG & $\mathrm{F}$ & EG & VG \\
\hline$C_{2}$ & MP & MG & MP & EG & MG & EG & EG & EG \\
\hline$C_{3}$ & MP & MG & MG & EG & MG & $\mathrm{F}$ & EP & EG \\
\hline$C_{4}$ & G & EG & EG & MG & MP & MG & VG & MG \\
\hline$C_{5}$ & MG & $\mathrm{F}$ & MP & $\mathrm{P}$ & $\mathrm{F}$ & MG & EG & EP \\
\hline$C_{6}$ & EG & $\mathrm{F}$ & MP & EP & EG & $\mathrm{F}$ & EP & EP \\
\hline$C_{7}$ & EG & $\mathrm{F}$ & VG & $\mathrm{F}$ & G & MP & MP & EG \\
\hline \multirow[t]{3}{*}{$C_{8}$} & MG & G & MG & MP & MG & EG & EG & EP \\
\hline & \multicolumn{4}{|c|}{ Expert 3's opinion } & \multicolumn{4}{|c|}{ Expert 4's opinion } \\
\hline & \begin{tabular}{|l|} 
South \\
Korea
\end{tabular} & Japan & Taiwan & China & $\begin{array}{l}\text { South } \\
\text { Korea }\end{array}$ & Japan & Taiwan & China \\
\hline$C_{1}$ & VG & MP & $\mathrm{F}$ & EP & MP & $\mathrm{F}$ & VG & $\mathrm{F}$ \\
\hline$C_{2}$ & EG & MG & MG & EP & $\mathrm{F}$ & G & VG & EP \\
\hline$C_{3}$ & MG & MG & G & G & MP & G & VG & MG \\
\hline$C_{4}$ & EP & MG & G & MG & $\mathrm{F}$ & G & G & $\mathrm{F}$ \\
\hline$C_{5}$ & MG & MP & EP & $\mathrm{F}$ & MG & MP & EG & VG \\
\hline$C_{6}$ & VG & F & VP & MP & G & MG & $\mathrm{F}$ & MP \\
\hline$C_{7}$ & MP & EG & MG & VG & EP & VG & $\mathrm{F}$ & $\mathrm{P}$ \\
\hline \multirow[t]{2}{*}{$C_{8}$} & EG & MG & $\mathrm{F}$ & MG & $\mathrm{G}$ & G & MG & $\mathrm{G}$ \\
\hline & \multicolumn{4}{|c|}{ Expert 5's opinion } & \multicolumn{4}{|c|}{ Expert 6's opinion } \\
\hline
\end{tabular}

\begin{tabular}{|c|c|c|c|c|c|c|c|c|}
\hline & $\begin{array}{l}\text { South } \\
\text { Korea }\end{array}$ & Japan & Taiwan & China & $\begin{array}{l}\text { South } \\
\text { Korea }\end{array}$ & Japan & Taiwan & China \\
\hline$C_{1}$ & $\mathrm{~F}$ & MG & $F$ & MP & $\mathrm{P}$ & VG & VG & $F$ \\
\hline$C_{2}$ & EG & VG & MP & $F$ & EG & EG & MP & EG \\
\hline$C_{3}$ & MG & $\mathrm{F}$ & $F$ & MG & MP & MG & EP & MG \\
\hline$C_{4}$ & EP & $\mathrm{P}$ & EG & VG & $\mathrm{VG}$ & $\mathrm{VG}$ & MP & MG \\
\hline$C_{5}$ & EG & VG & EP & EP & MP & $P$ & MP & EG \\
\hline$C_{6}$ & MG & MG & $\mathrm{P}$ & EP & EP & MG & $\mathrm{P}$ & EP \\
\hline$C_{7}$ & $\mathrm{~F}$ & EG & MG & $F$ & $\mathrm{~F}$ & MP & $F$ & $\mathrm{P}$ \\
\hline \multirow[t]{3}{*}{$C_{8}$} & MP & $\mathrm{F}$ & MG & VG & VG & $\mathrm{F}$ & $\mathrm{P}$ & MG \\
\hline & \multicolumn{4}{|c|}{ Expert 7's opinion } & \multicolumn{4}{|c|}{ Expert 8's opinion } \\
\hline & \begin{tabular}{|l|} 
South \\
Korea
\end{tabular} & Japan & Taiwan & China & $\begin{array}{l}\text { South } \\
\text { Korea }\end{array}$ & Japan & Taiwan & China \\
\hline$C_{1}$ & MP & $\mathrm{F}$ & $\mathrm{VG}$ & $\mathrm{P}$ & VG & G & $\mathrm{P}$ & MP \\
\hline$C_{2}$ & MG & VG & MP & MP & $\mathrm{F}$ & EG & MG & MP \\
\hline$C_{3}$ & EG & $\mathrm{F}$ & MG & EG & MG & $\mathrm{VG}$ & MG & VG \\
\hline$C_{4}$ & EP & $\mathrm{P}$ & $F$ & $F$ & $\mathrm{~F}$ & $F$ & EG & VG \\
\hline$C_{5}$ & EG & MG & MP & EP & MG & EG & $\mathrm{F}$ & VG \\
\hline$C_{6}$ & EP & $\mathrm{F}$ & EP & $\mathrm{P}$ & $\mathrm{VG}$ & MG & EP & MP \\
\hline$C_{7}$ & EP & MP & EG & $P$ & MP & EG & VG & MG \\
\hline \multirow[t]{3}{*}{$C_{8}$} & EP & VG & $\mathrm{P}$ & $\mathrm{VG}$ & $\mathrm{P}$ & $\mathrm{VG}$ & $F$ & $\mathrm{P}$ \\
\hline & \multicolumn{4}{|c|}{ Expert 9's opinion } & & & & \\
\hline & \begin{tabular}{|l|} 
South \\
Korea \\
\end{tabular} & Japan & Taiwan & China & & & & \\
\hline$C_{1}$ & EG & $\mathrm{G}$ & MG & MG & & & & \\
\hline$C_{2}$ & $\mathrm{~F}$ & EG & MP & MP & & & & \\
\hline$C_{3}$ & $\mathrm{~F}$ & MG & $\mathrm{F}$ & $\mathrm{VG}$ & & & & \\
\hline$C_{4}$ & MP & MP & $\mathrm{VP}$ & MG & & & & \\
\hline$C_{5}$ & $\mathrm{G}$ & MP & MP & $\mathrm{P}$ & & & & \\
\hline$C_{6}$ & VG & EG & EP & EP & & & & \\
\hline$C_{7}$ & $\mathrm{P}$ & $\mathrm{P}$ & $F$ & $F$ & & & & \\
\hline$C_{8}$ & MG & VG & VG & EG & & & & \\
\hline
\end{tabular}

Step 4. Calculate weight (importance) of each criterion

In this work, we use entropy method (Refer to equation 7) to calculated weight of each criteria. Analysis result can refer to Table 5 .

Table 5: Weight of each criterion

\begin{tabular}{|c|c|c|c|c|}
\hline Criteria & $C_{1}$ & $C_{2}$ & $C_{3}$ & $C_{4}$ \\
\hline Weight & 0.1246 & 0.1902 & 0.1600 & 0.1190 \\
\hline Criteria & $C_{5}$ & $C_{6}$ & $C_{7}$ & $C_{8}$ \\
\hline Weight & 0.0656 & 0.1043 & 0.0906 & 0.1457 \\
\hline
\end{tabular}

In this study, the rank of each research target (region) in medical tourism industry is decided by VIKOR method. The advantage of VIKOR is that VIKOR can solve decision problems with conflicting criteria. In this research, medical ability $\left(C_{2}\right)$ and medical service speed in hospital $\left(C_{7}\right)$ are conflicting criteria. Industry image $\left(C_{1}\right)$ and medical cost $\left(C_{4}\right)$ are conflicting criteria.

\section{Step 5. Calculate PIS and NIS}

Positive ideal solution (PIS) is the ideal status for medical tourism industry in Asia. On the opposite direction, negative ideal solution the worst status for medical tourism industry in Asia. PIS and NIS are reference points used to evaluate performance of each medical tourism industry (research target). Equation 8 and equation 9 are employed to calculate PIS and NIS. Analysis result can refer to Table 6 . 
Table 6: PIS and NIS

\begin{tabular}{|c|c|c|c|c|}
\hline \multirow{3}{*}{ PIS } & $C_{1}$ & $C_{2}$ & $C_{3}$ & $C_{4}$ \\
\cline { 2 - 5 } & 0.7344 & 0.9688 & 0.9219 & 0.7969 \\
\cline { 2 - 5 } & $C_{5}$ & $C_{6}$ & $C_{7}$ & $C_{8}$ \\
\cline { 2 - 5 } & 0.7656 & 0.7500 & 0.7344 & 0.8438 \\
\hline \multirow{7}{*}{ NIS } & $C_{1}$ & $C_{2}$ & $C_{3}$ & $C_{4}$ \\
\cline { 2 - 5 } & 0.5156 & 0.5781 & 0.5625 & 0.4219 \\
\cline { 2 - 5 } & $C_{5}$ & $C_{6}$ & $C_{7}$ & $C_{8}$ \\
\cline { 2 - 5 } & 0.4688 & 0.1719 & 0.4688 & 0.6406 \\
\hline
\end{tabular}

Step 6. Calculate total performance of research target $S_{i}$ and the individual regret value of research target $R_{i}$.

Total performance of research target $S_{i}$ means the entire performance of research target $T_{i}$. Individual regret value of research target $R_{i}$ means the maximum regret degree of experts if he/she select research target $T_{i}$. $S_{i}$ and $R_{i}$ separately represents performance analysis result of research target based on different analysis direction. Equation 10 and equation 11 are employed to calculate $S_{i}$ and $R_{i}$. Analysis result can refer to Table 7 .

Step 7. Calculate $Q$ value

In this research, decision parameter $\mathrm{v}$ is set up as 0.5 . We consider that the evaluation index $S_{i}$ and $R_{i}$ is important equally. Equation 12 are employed to calculated $Q$ value. Analysis result can refer to Table 7. According to analysis result, the rank of each region is $T_{2}>T_{1}>T_{3}>T_{4}$. The competitiveness rank sequence of medical tourism industry in Asia is Japan, South Korea, Taiwan and China.

Table 7: Total performance, individual regret value, $\mathrm{Q}$ value and rank among each medical tourism industry in Asia

\begin{tabular}{|l|c|c|c|c|}
\hline & $\begin{array}{c}\text { South } \\
\text { Korea } \\
\left(T_{1}\right)\end{array}$ & $\begin{array}{c}\text { Japan } \\
\left(T_{2}\right)\end{array}$ & $\begin{array}{c}\text { Taiwan } \\
\left(T_{3}\right)\end{array}$ & $\begin{array}{c}\text { China } \\
\left(T_{4}\right)\end{array}$ \\
\hline $\begin{array}{l}\text { Total } \\
\text { performance } \\
\text { of research } \\
\text { target } S_{i}\end{array}$ & 0.5795 & 0.1897 & 0.6310 & 0.6758 \\
\hline $\begin{array}{l}\text { Individual } \\
\text { regret value of } \\
\text { research target } \\
R_{i}\end{array}$ & 0.1457 & 0.0974 & 0.1674 & 0.1902 \\
\hline Q value & 0.6612 & 0.0000 & 0.8310 & 1.0000 \\
\hline Rank & 2 & 1 & 3 & 4 \\
\hline
\end{tabular}

Step 8. SWOT Analysis

According to experts' opinion (Refer to Figure 3), Taiwan medical industry possesses some strength is the dimension of medical cost $\left(C_{4}\right)$ and medical service speed in hospital $\left(C_{7}\right)$. However, Taiwan medical industry should take effort in the dimension of medical industry image $\left(C_{1}\right)$, medical ability $\left(C_{2}\right)$ and telemedicine ability $\left(C_{3}\right)$. Medical ability and telemedicine ability of Taiwan medical industry will influence foreigners' medical industry image for Taiwan. Because volume of medical tourism traveler per year $\left(C_{6}\right)$ in Taiwan is relatively small, Taiwan possesses high growth space to develop in the medical tourism market. Compare with south Korea, Japan and China,
Taiwan lack scale economics in medical industry because financial status in hospital and travel agency $\left(C_{5}\right)$, maximum service volume in region $\left(C_{8}\right)$ is relatively small. The disadvantage of scale economics in Taiwan will cause that it is hard to reduce Taiwan's overall medical costs and is not easy to enhance Taiwan's overall medical industry image (Refer to Table $8)$.

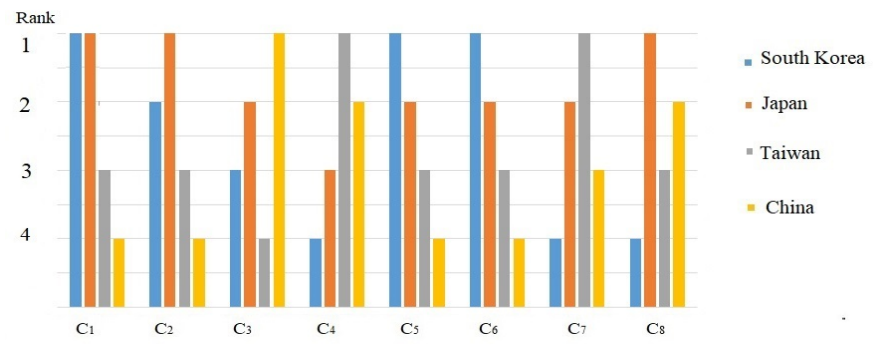

Figure 3: Rank of each region among different dimension

Table 8: SWOT analysis for Taiwan medical tourism industry

\begin{tabular}{l|l|}
$\begin{array}{l}\text { Strengths } \\
\text { (1) Medical cost is relatively } \\
\text { cheap. } \\
\text { (2) Medical service speed is } \\
\text { relatively fast. }\end{array}$ & $\begin{array}{l}\text { Weaknesses } \\
\text { (1) Taiwan medical industry } \\
\text { image from tourism traveler } \\
\text { is relatively less well- } \\
\text { known. } \\
\text { (2) Medical ability is weak. } \\
\text { (3) Telemedicine ability is } \\
\text { weak. }\end{array}$ \\
$\begin{array}{l}\text { Opportunities } \\
\text { (1) Volume of medical tourism } \\
\text { traveler is relatively small. }\end{array}$ & $\begin{array}{l}\text { Threats } \\
\text { (1) Financial status in } \\
\text { hospital and travel agency is } \\
\text { relatively small } \\
\text { (2) Maximum service } \\
\text { volume in region is } \\
\text { relatively small }\end{array}$ \\
\hline
\end{tabular}

\section{Management Implementation}

According to experts' opinion, Taiwan possesses high growth space to develop in the medical tourism market because medical cost in Taiwan is relatively cheap which can attract some foreigner whose economics ability is not good enough to receive high price medical service in Japan or South Korea. There are some policies which can promote the competitiveness for Taiwan tourism medical industry.

\subsection{Increase volume of medical students each year}

There are only 1,300 new students who can enter to study department of medicine in Taiwan each year. Under this total control policy, although Taiwan can maintain high medical standards, it cannot improve Taiwan's medical energy to meet the needs of additional medical services for foreign patients.

\subsection{Build overseas medical zone}

Taiwan has implemented universal health insurance. Therefore, Taiwan citizen can use low-cost medical services. However, the purpose of developing medical tourism industry is to increase Taiwan's overall GDP. It is unfair to Taiwan citizens if charging standards for foreign patients and Taiwan citizens are the same. Doctor and nurse should use English to serve foreign patients. 
This is also a language threshold to develop medical tourism industry.

In order to compete with foreign medical institutions, this study suggests that Taiwan should set up an overseas medical zone. The hospitals in the zone are dedicated to treating foreign patients. It is beneficial to the development for Taiwan's medical tourism industry.

\subsection{Development of telemedicine technology}

The occurrence of COVID-19 in 2019 has caused the stagnation of the tourism industry in various countries around the world. This event has also affected the development of medical tourism. The medical tourism industry needs to maintain relationship with foreign patients. Telemedicine technology is an important means for hospitals to maintain relationship with foreign patients when international tourism activity cannot be implemented during 2019-2020. Taiwan's medical tourism industry should strengthen and improve telemedicine technology.

\subsection{Develop overseas free clinic activities}

Taiwan's medical industry is less well-known than south Korea and Japan. Taiwan should go to various countries in southeast Asia and central Asia for free consultations. This will not only enhance Taiwan's medical industry image but also increase the potential patience source for Taiwan's medical tourism industry. The world's low-end industrial manufacturing order may move from China to various countries in southeast Asia and central Asia. Therefore, people from countries in southeast asia and central asia will gradually have the ability to travel to Taiwan for receiving medical service.

\section{Conclusion}

Medical tourism is very important industry in many countries. A novel framework for evaluating competitiveness of medical tourism industry has been designed in this research. South Korea, Japan, Taiwan and China are selected as research target to evaluate their competitive ability. According to analysis result, we find out that Taiwan's medical tourism competitiveness falls in backward group. So, Taiwan government should provide more resource to improve its medical tourism competitive ability for developing medical tourism industry especially some citizen in other country such as America has high motivation to go abroad for medical treatment because medical expenses is too expensive in America. So, this research provides four suggestion to Taiwan government.

In the future, relative scholar can use this model to evaluate competitiveness of medical tourism industry among Asian countries and European countries. Scholar can analyze how the cultural difference can influence the rank of medical tourism competitiveness.

\section{Conflict of Interest}

The authors declare no conflict of interest.

\section{Acknowledgement}

I state that the data in this research collect from experts in each field and experts' occupation includes government officer, employees in traditional hotel, employees in travel agency, nurse leader, doctor (hospital dean) and university professors. Other scholars can use the data to execute extended research.

\section{References}

[1] I. Sophie, "Revealed: Countries With The Best Health Care Systems. CEOWORLD Manazine," https://ceoworld.biz/2019/08/05/revealedcountries-with-the-best-health-care-systems-2019/, 2019.

[2] H. M. Chen, C. H. Tseng, "The performance of marketing alliances between the tourism industry and credit card issuing banks in Taiwan," Tourism Management, 26, 15-24, 2005.

[3] S. Gössling, D., Scott, C. M. Hall, "Pandemics, tourism and global change: a rapid assessment of COVID-19," Journal of Sustainable Tourism, 1-20, 2020. https://doi.org/10.1080/09669582.2020.1758708

[4] L. Qi, Y. X. Zhuo, S. Cai, "Taiwan's international medical tourism development strategy," Taiwan Medical Circle, 55(8), 48-51, 2012. https://doi.org/10.11634/216837861403126

[5] T. H. Chang, "Fuzzy VIKOR method: a case study of the hospital service evaluation in Taiwan," Information Sciences, 271, 196-212, 2014. https://doi.org/10.1016/j.ins.2014.02.118

[6] A. M. Sharifabadi, F. A. Ardakani, "A model for health tourism development using fuzzy TOPSIS and interpretive structural modeling in Yazd province," Journal of Health Administration (JHA), 17(55), 73-88, 2014.

[7] Z. Awang, A. Afthanorhan, M. Mohamad, M. A. M. Asri, "An evaluation of measurement model for medical tourism research: the confirmatory factor analysis approach," International Journal of Tourism Policy, 6, 29-45, 2015.

[8] A. Görener, "A. swot-ahp approach for assessment of medical tourism sector in Turkey," Alphanumeric Journal, 4, 159-170, 2016.

[9] P. Ajmera, "Ranking the strategies for Indian medical tourism sector through the integration of SWOT analysis and TOPSIS method," International Journal of Health Care Quality Assurance, 30, 668-679, 2017.

[10] F. Abadi, I. Sahebi, A. Arab, A. Alavi, H. Karachi, "Application of bestworst method in evaluation of medical tourism development strategy," Decision Science Letters, 7(1), 77-86, 2018.

[11] J. Roy, K. Chatterjee, A. Bandyopadhyay, S. Kar, "Evaluation and selection of medical tourism sites: A rough analytic hierarchy process based multiattributive border approximation area comparison approach," Expert Systems, 35, 12232, 2018.

[12] M. Nilashi, S. Samad, A. A. Manaf, H. Ahmadi, T. A. Rashid, A. Munshi, W. Almukadi, O. Othman Ibrahim, O. H. Ahmed, "Factors influencing medical tourism adoption in Malaysia: A DEMATEL-Fuzzy TOPSIS approach," Computers \& Industrial Engineering, 137, 106005, 2019.

[13] A. Singh, "An integrated approach towards ranking hospitals using Fuzzy AHP and ELECTRE-I technique," International Journal of Healthcare Management, 1-10, 2019. https://doi.org/10.1016/j.ins.2014.02.118

[14] J. Takacs, S. A. Vaduva, "A swot analysis of the global hospitality industry," Revista Economica, 69(6), 105-119, 2017.

[15] A. Reihanian, N. Z. B. Mahmood, E. Kahrom, T. W. Hin, "Sustainable tourism development strategy by SWOT analysis: Boujagh National Park," Iran. tourism management Perspectives, 4, 223-228, 2012.

[16] P. Liu, F. Teng, "An extended TODIM method for multiple attribute group decision-making based on 2-dimension uncertain linguistic Variable," Complexity, 21, 20-30, 2016.

[17] L. A. Zadeh, "The concept of a linguistic variable and its application to approximate reasoning," Learning systems and intelligent robots. Springer, Boston, MA, 1-10, 1974.

[18] F. Herrera, L. Martinez, "The 2-tuple linguistic computational model: Advantages of its linguistic description, accuracy and consistency," International Journal of Uncertainty, Fuzziness and Knowledge-Based Systems, 9, 33-48, 2001.

[19] A. I. A1 Maghsoodi, G. Abouhamzeh, M. Khalilzadeh, E. K. Zavadskas, "Ranking and selecting the best performance appraisal method using the MULTIMOORA approach integrated Shannon's entropy," Frontiers of Business Research in China, 12(1), 2018.

[20] R. Levy, J. P. F. LeBlanc, E. Gull, "Implementation of the maximum entropy method for analytic continuation," Computer Physics Communications, 215, 149-155, 2017. https://doi.org/10.1016/j.cpc.2017.01.018

[21] W. Huang, B. Shuai, Y. Sun, Y. Wang, E. Antwi, "Using entropy-TOPSIS method to evaluate urban rail transit system operation performance: The China case," Transportation Research Part A: Policy and Practice, 111, 292303, 2018.

[22] A. De Nisco, G. Mainolfi, V. Marino, M. R. Napolitano, "Tourism 
satisfaction effect on general country image, destination image, and postvisit intentions," Journal of Vacation Marketing, 21(4), 305-317, 2015.

[23] S. Chaulagain, J. Wiitala, X. Fu, X. "The impact of country image and destination image on US tourists' travel intention," Journal of Destination Marketing \& Management, 12, 1-11, 2019.

[24] C. R. Peters, K. M. Sauer, "A survey of medical tourism service providers," Journal of Marketing Development and Competitiveness, 5(3), 117-126, 2011.

[25] J. Connell, "Contemporary medical tourism: Conceptualisation, culture and commodification," Tourism management, 34, 1-13, 2013.

[26] W. Bies, L., Zacharia, "Medical tourism: outsourcing surgery," Mathematical and Computer Modelling, 46(7-8), 1144-1159, 2007.

[27] D. York, "Medical tourism: the trend toward outsourcing medical procedures to foreign countries," Journal of Continuing Education in the Health Professions, 28(2), 99-102, 2008.

[28] D. S. Kc, C. Terwiesch, "Impact of workload on service time and patient safety: An econometric analysis of hospital operations," Management Science, 55(9), 1486-1498, 2009.

[29] H. E. Frech III, L. R. Mobley, "Resolving the impasse on hospital scale economics: a new approach," Applied Economics, 27(3), 286-296, 1995.

[30] L. Mart1, F. Herrera, "An overview on the 2-tuple linguistic model for computing with words in decision making: Extensions, applications and challenges," Information Sciences, 207, 1-18, 2012.

[31] J. H. Wang, J. Hao, "A new version of 2-tuple fuzzy linguistic representation model for computing with words," IEEE transactions on Fuzzy Systems, 14, 435-445, 2006. 